\title{
Computationally-Assisted Approach to the Vibrational Spectra of Molecular Crystals: Study of Hydrogen-Bonding and Pseudo- Polymorphism**
}

\author{
Mariela M. Nolasco, ${ }^{[a]}$ Ana M. Amado, ${ }^{[b]}$ and Paulo J. A. Ribeiro-Claro*[a]
}

A new computationally-assisted methodology (PiMM), which accounts for the effects of intermolecular interactions in the crystal, is applied to the complete assignment of the Raman and infrared vibrational spectra of room temperature forms of crystalline caffeine, theobromine, and theophylline. The vibrational shifts due to crystal packing interactions are evaluated from $a b$ initio calculations for a set of suitable molecular pairs, using the B3LYP/6$31 G^{*}$ approach.The proposed methodology provides an answer to the current demand for a reliable assignment of the vibration- al spectra of these methyl-xanthines, and clarifies several misleading assignments. The most relevant intermolecular interactions in each system and their effect on the vibrational spectra are considered and discussed. Based on these results, significant insights are obtained for the structure of caffeine in the anhydrous form (stable at room temperature), for which no $X$-ray structure has been reported. A possible structure based on $\mathrm{C}_{(8)}$ $H \cdots N_{(9)}$ and $C_{(1,3)}-H \cdots O$ intermolecular interactions is suggested.

\section{Introduction}

Caffeine (1,3,7-trimethylpurine-2,6-dione; CA), theophylline (1,3-dimethylpurine-2,6-dione; TP), and theobromine (3,7-dimethylpurine-2,6-dione; TB) are three methylated xanthine derivatives (see Figure 1) widely found in the human diet that represent three different systems of important pharmaceutical interest. They naturally occur in food products such as tea, coffee, and cocoa beans (with TB and CA being the two most abundant xanthines in chocolate, for instance). On the other hand, these compounds are also used in a variety of medical applications, being routinely prescribed. For instance, CA is used as a central nervous system, cardiac and respiratory stimulant, while TP and TB are widely used as smooth muscle relaxants.<smiles>Cn1c(=O)c2[nH]cnc2n(C)c1=O</smiles>

$$
\text { TB }
$$<smiles>Cn1cnc2c1c(=O)[nH]c(=O)n2C</smiles><smiles>Cn1c(=O)c2c(ncn2C)n(C)c1=O</smiles>

Figure 1. Schematic representation of the xanthine derivatives: theophylline (TP), theobromine (TB), and caffeine (CA).
TP is also used as a bronchodilator, for the treatment of bronchial asthma and neonatal apneia ${ }^{[1]}$ and in the treatment of epilepsy. ${ }^{[2]}$ All three compounds are also known to cause diure$\mathrm{sis}^{[3]}$ while CA administration seems to protect mice against a whole-body lethal dose of $\gamma$-irradiation. ${ }^{[4]}$

The polymorphic behavior of drugs is a major concern of the pharmaceutical industry since different packing arrangements of the same molecular species (polymorphism) can have markedly different biopharmaceutical properties. ${ }^{[5]}$ It is well documented that CA and TP are sensitive to polymorphic and pseudo-polymorphic transformations that affect their dissolution profiles and, consequently, their bioavailability. ${ }^{[6-11]}$ In fact, they crystallize into different states (hydrate and anhydrous $)^{[12-15]}$ and are good model compounds for the accurate characterization of both the polymorphic form and hydration states.

In this way, the knowledge of the structural characteristics of these compounds from a molecular point of view is of utmost relevance for a rational understanding of the structure-activity

[a] Dr. M. M. Nolasco, Prof. P. J. A. Ribeiro-Claro

CICECO, Departamento de Química

Universidade de Aveiro, 3810-193 Aveiro (Portugal)

Fax: (+351) 234370084

E-mail:pclaro@dq.ua.pt

[b] Dr. A. M. Amado

Química-Física Molecular, Departamento de Química

FCTUC, Universidade de Coimbra

3004-535 Coimbra (Portugal)

Fax: (+ 351) 239826541

${ }^{[* *}$ in Theophylline, Theobromine, and Caffeine. 
relationship ruling their biochemical effects. In this context, the analysis of the vibrational spectra (Raman and FTIR), in particular of CA and TP, has aroused considerable interest. ${ }^{[6,16-22]}$ However, to the best of our knowledge, no complete vibrational assignment has been attempted yet and the complete and reliable assignment of the vibrational spectra of these compounds is naturally justified. Very recently some works showed the vibrational spectra of $C A, T P$, and $\mathrm{TB}_{1}^{[6,12,19-21,23]}$ but, unfortunately, including incomplete, questionable and even misleading assignments, as reported previously by some of us. ${ }^{[22]}$

The complete assignment of the vibrational spectra of relatively complex molecules in the crystalline state is quite difficult, and the assignment of some experimentally observed bands to specific vibrations is usually uncertain. In order to assist this difficulty, theoretical calculations are used to support a reliable assignment by comparing the theoretically calculated spectra with the experimentally observed ones. The usefulness of theoretical calculations, particularly using density functional theory (DFT) methods, to assist vibrational spectroscopic studies has been recently highlighted. ${ }^{[24]}$

The present paper has been organized as follows. Firstly, the PiMM methodology (Pairs in Molecular Materials) is presented. Secondly, the results are discussed in two sections 1 ) the description of the crystal structures of xanthine derivatives based on ab initio calculations at the B3LYP/6-31G* level; 2) the complete assignment, based on the computationally-assisted methodology, of the FT-Raman and FTIR spectra of TB, TP, and CA and their pseudopolymorphs.

\section{Results and Discussion}

\subsection{Methodology}

The computationally-assisted methodology for vibrational spectra assignment used is based on the frequency and intensity calculations, for fully-optimized geometry structures, at the B3LYP/6-31G* level. This approach-vibrational spectra assignment by comparison with suitable simulated spectra-has been successfully applied for a couple of systems ${ }^{[25-28]}$ and is generally recognized as a reliable approach. ${ }^{[24]}$ On the other hand, the B3LYP/6-31G* level is known to provide a good "quality/computational cost ratio" for both geometry optimizations and vibrational spectra simulations in organic systems.

The major limitation of ab initio calculations in what concerns the prediction of the vibrational spectra arises from the complexity of the calculations involved, which imposes severe limitations on the size of the system. Despite the development of computers, it is still difficult to deal with systems of more than a few dozens of atoms. In this way, most of the frequency and intensity calculations refer to the single molecule situation. The calculated spectrum for the single molecule is expected to describe the gas phase spectra, and can be used with caution to simulate liquid phase and solution spectra, but fails to describe properly the solid-state spectra. The error is as large as the strong intermolecular interactions in the solid state.

A possible approach to overcome this limitation, proposed in this work, is to assume that the intermolecular interactions in the crystal perturb the wavenumbers of the isolated molecule. Within this approach, the wavenumber of the ith normal mode is given by its calculated wavenumber in the isolated molecule, corrected for the perturbations resulting from the contacts with neighbouring molecules in the crystal as represented in Equation (1):

$$
\begin{aligned}
v_{\mathrm{i}}(\text { crystal })= & v_{\mathrm{i}}(\text { isolated })+\sum \Delta v_{\mathrm{i}}{ }^{(1)}(\text { direct })+\sum \Delta v_{\mathrm{i}}^{(1)}(\text { indirect }) \\
& +\sum \Delta v_{\mathrm{i}}^{(2)}(\text { direct })+\sum \Delta v_{\mathrm{i}}^{(2)}(\text { indirect })+\ldots
\end{aligned}
$$

where the term "direct" refers to the effect of the intermolecular contacts on the oscillators involved in the contact (e.g. the effect of a $\mathrm{O}-\mathrm{H} \cdots \mathrm{O}$ hydrogen bond on the $\mathrm{O}-\mathrm{H}$ vibrational modes), while the term "indirect" refers to the effect of the same contact on the remaining modes (e.g. the effect of a O$\mathrm{H}$... O hydrogen bond on the modes involving oscillators in other parts of the molecule), and the summation applies to all possible contacts. The superscripts (1), (2) apply respectively to the first and second shell of neighbors.

Assuming that only the neighbors in the first shell significantly affect the calculated wavenumbers of the isolated molecule, Equation (1) simplifies to [Eq. (2)]

$$
v_{\mathrm{i}}(\text { crystal })=v_{\mathrm{i}}(\text { isolated })+\sum \Delta v_{\mathrm{i}}^{(1)}(\text { direct })+\sum \Delta v_{\mathrm{i}}{ }^{(1)}(\text { indirect })
$$

and the corrections can be obtained by frequency calculations for all the molecular pairs required to describe the different intermolecular contacts present in the crystal (after full-geometry optimization).

The simplified version shown in Equation (2) neglects the effects of long-range interactions and the cooperativity of the various interactions. Although it is difficult to fully quantify the importance of these effects, it can be estimated by comparing the results for molecular pairs with those obtained for larger associations of molecules. From a set of calculations performed for associations of three and four molecules, these effects are estimated to affect the predicted shifts, on average, by less than $\approx 5 \mathrm{~cm}^{-1}$. However, differences of $\approx 25-35 \mathrm{~cm}^{-1}$ are observed in the most sensitive modes.

\subsection{Selection of Relevant Molecular Pairs from the Crystal Structures}

The crystal structures of the three methyl xanthines considered, present networks of hydrogen bonds which are expected to have a significant effect on the corresponding vibrational spectra. ${ }^{[13-15,29-33]}$ The application of the previously described methodology requires ab initio calculations on molecular pairs that simulate the molecular associations found in the solid structures. In the case of TP and CA, the crystal structures of both hydrate forms (hereafter named TPh and CAh, respectively) and anhydrate forms (hereafter named TPa and CAa, respectively) must be considered, while for TB only the anhy- 
drous form (hereafter named TBa) is known to exist. It is to be noted, however, that the crystal structure of anhydrous CA (known to exist as two different polymorphic forms, namely $\alpha$ and $\beta$-forms ${ }^{[34]}$ ) has not been determined as only powders and disordered crystals are obtained. ${ }^{[35]}$

Figure 2 shows the most important intermolecular hydrogen bonds found in the crystal packing of the methyl-xanthine derivatives studied. Each interaction is described by one of the<smiles>Cn1c(=O)c2nncn2n(C)c1=O</smiles>

TB<smiles>[Y10][14C](O)n1c(=O)c2c(nc([Y10]#[W])n2C)n(C)c1=O</smiles>

TP<smiles></smiles>

CA<smiles></smiles>

Figure 2. Atom numbering of xanthine derivatives and schematic representation of the molecular pairs with relevant intermolecular contacts observed in the crystal structures retrieved from the Cambridge Structural Database (ref. code indicated): pair I (theophylline anydrous, BAPLOT01 [14]), pairs IIV(theophylline hydrate, THEOPH/THEOPH01 [29]), pairs VI and VII (theobromine anydrous, SEDNAQ [13]), pairs VII-X (caffeine hydrate, CAFINE/ CAFINE01 [30]). $\mathrm{O}_{w}$ represents the oxygen atom from the water molecule.

molecular pairs $\mathrm{I}-\mathrm{X}$ indicated (for instance, molecular pair $\mathrm{I}$ is built from two TP molecules linked by a $\mathrm{N}_{(7)}-\mathrm{H} \cdots \mathrm{N}_{(9)}$ hydrogen bond). Among the methyl-xanthine derivatives considered, TP is the one for which the crystal structures of both forms (anhydrate and hydrate) are known. Thus, TP is the best model to demonstrate the application of the computationally-assisted methodology proposed. In this context, the packing analysis of the crystal structures of TPh and TPa forms, and the ab initio studies required to describe the intermolecular contacts present in each case, are discussed in more detail.

\subsubsection{Theophylline}

The crystal structures of both TPh and TPa forms show that all groups but one are involved in intermolecular hydrogen bonding, although there are significant differences in the donor/acceptor pairing between the two forms. The exception is the methyl group at position $\mathrm{N}_{(3)}$, which does not participate in any hydrogen bond neither in the hydrate structure nor in the anhydrous structure. A characteristic feature of the monohydrated structure is the existence of heaped layers of dimeric structures of TP molecules, related by a centre of symmetry, which are held together by two types of TP...TP interactions, namely $\mathrm{N}_{(7)}-\mathrm{H} \cdots \mathrm{O}_{(6)}$ and $\mathrm{C}_{(8)}-\mathrm{H} \cdots \mathrm{O}_{(2)}$ (each TP molecule establish- ing two equivalent interactions of each type, thus acting both as a donor and as an acceptor). In addition, each TP molecule establishes two types of TP... $\mathrm{H}_{2} \mathrm{O}$ interactions $\left(\mathrm{N}_{(9)} \cdots \cdot \mathrm{H}-\mathrm{O}_{\mathrm{w}}\right.$ and $\left.\mathrm{C}_{(1)}-\mathrm{H} \cdots \mathrm{O}_{\mathrm{w}}\right)$, forming water network channels that cross the different TP molecular layers. In turn, the crystal structure of the anhydrous form has no defined layers. In fact, the planar TP molecules are stacked in columns, where the interplanar angle between adjacent TP molecules of $43^{\circ}$. These columns are held together by $\mathrm{N}_{(7)}-\mathrm{H} \cdots \mathrm{N}_{(9)}$ hydrogen bonds.

Figure 2 presents the optimized structures of the different TP molecular pairs that simulate the different intermolecular interactions (TP...TP and $\mathrm{TP}^{\mathrm{N}} \mathrm{H}_{2} \mathrm{O}$ ) present in the solid structures of either TPh or TPa forms. In all cases, the calculated intermolecular distance of the interaction is indicated. It should be mentioned that the TP molecule can occur in four tautomeric forms, namely $\operatorname{TP}\left(\mathrm{N}_{(7)} \mathrm{H}\right), \operatorname{TP}\left(\mathrm{N}_{(9)} \mathrm{H}\right), \operatorname{TP}\left(\mathrm{O}_{(2)} \mathrm{H}\right)$, and $\operatorname{TP}\left(\mathrm{O}_{(6)} \mathrm{H}\right)$. However, the $\mathrm{X}$-ray results demonstrate that in the crystalline state, the $\operatorname{TP}\left(\mathrm{N}_{(7)} \mathrm{H}\right)$ tautomer is prevalent. ${ }^{[14]}$ Moreover, the ab initio calculations are in agreement with this observation, since the energy difference between the lowest-energy tautomeric form $\operatorname{TP}\left(\mathrm{N}_{(7)} \mathrm{H}\right)$ and the second most stable form $\left[\operatorname{TP}\left(\mathrm{N}_{(9)} \mathrm{H}\right)\right]$ is larger than $38 \mathrm{~kJ} \mathrm{~mol}^{-1}$. In this way, all the molecular pairs in Figure 3 were built up from the $\operatorname{TP}\left(\mathrm{N}_{(7)} \mathrm{H}\right)$ tautomeric form.

Molecular pair I represents the intermolecular contacts characteristic of the TPa form (TP dimer structures held by $\mathrm{N}_{(7)}$ $\mathrm{H} \cdot \cdots \mathrm{N}_{(9)}$ interactions), while molecular pairs II, III, IV, and V represent the four distinct molecular associations that are evident in the TPh crystal structure (molecular associations held through $\mathrm{N}_{(7)}-\mathrm{H} \cdots \mathrm{O}_{(6)}$ and $\mathrm{C}_{(8)}-\mathrm{H} \cdots \mathrm{O}_{(2)}, \mathrm{N}_{(9} \cdots \mathrm{H}-\mathrm{O}_{\mathrm{w}}$ and $\mathrm{C}_{(1)}-\mathrm{H} \cdots \mathrm{O}_{\mathrm{w}}$ interactions). Molecular pair II, which presents two strong $\mathrm{N}_{(7)}-\mathrm{H} \cdots \mathrm{O}_{(6)}$ interactions, corresponds to the lowest energy minimum found. The predicted $\mathrm{N}-\mathrm{H} \cdots \mathrm{O}$ distance is $177 \mathrm{ppm}$, which is in good agreement with the reported X-ray value, 190 ppm, ${ }^{[29]}$ taking into account the distinct nature of the two methods. Molecular pair III, which is built by a weaker intermolecular interaction $\left(\mathrm{C}_{(8)}-\mathrm{H} \ldots \mathrm{O}_{(2)}\right)$, corresponds to the less stable TP...TP dimer. Despite their weakness, $\mathrm{C}-\mathrm{H}$...O hydrogen bonds are known to play a significant role in crystal packing and have major effects on the vibrational spectra of molecular systems. ${ }^{[25,27,28]}$

Table 1 presents the predicted ab initio wavenumbers for the TP monomer and the wavenumber shifts promoted by considering the different molecular pairs of Figure 3 (only the modes that are significantly affected by the intermolecular contacts are shown).

\subsubsection{Theobromine and Caffeine}

Figures 4 and 5 show the molecular pairs which characterize the crystal structures of TBa and CAh, respectively. Starting with the TBa, a characteristic feature of its crystal structure is the association of TB molecules resulting in pseudo-centrosymmetric structures linked by two intermolecular $\mathrm{N}_{(1)}-\mathrm{H} \cdots \mathrm{O}_{(2)}$ hydrogen bonds (molecular pair VI of Figure 4). ${ }^{[13]}$ These molecular pairs are held together through weaker $\mathrm{C}_{(8)}-\mathrm{H} \cdots \mathrm{O}_{(6)}$ hydrogen bonds between adjacent molecules (molecular pair VII in Figure 4), forming a two-dimensional layered structure. 

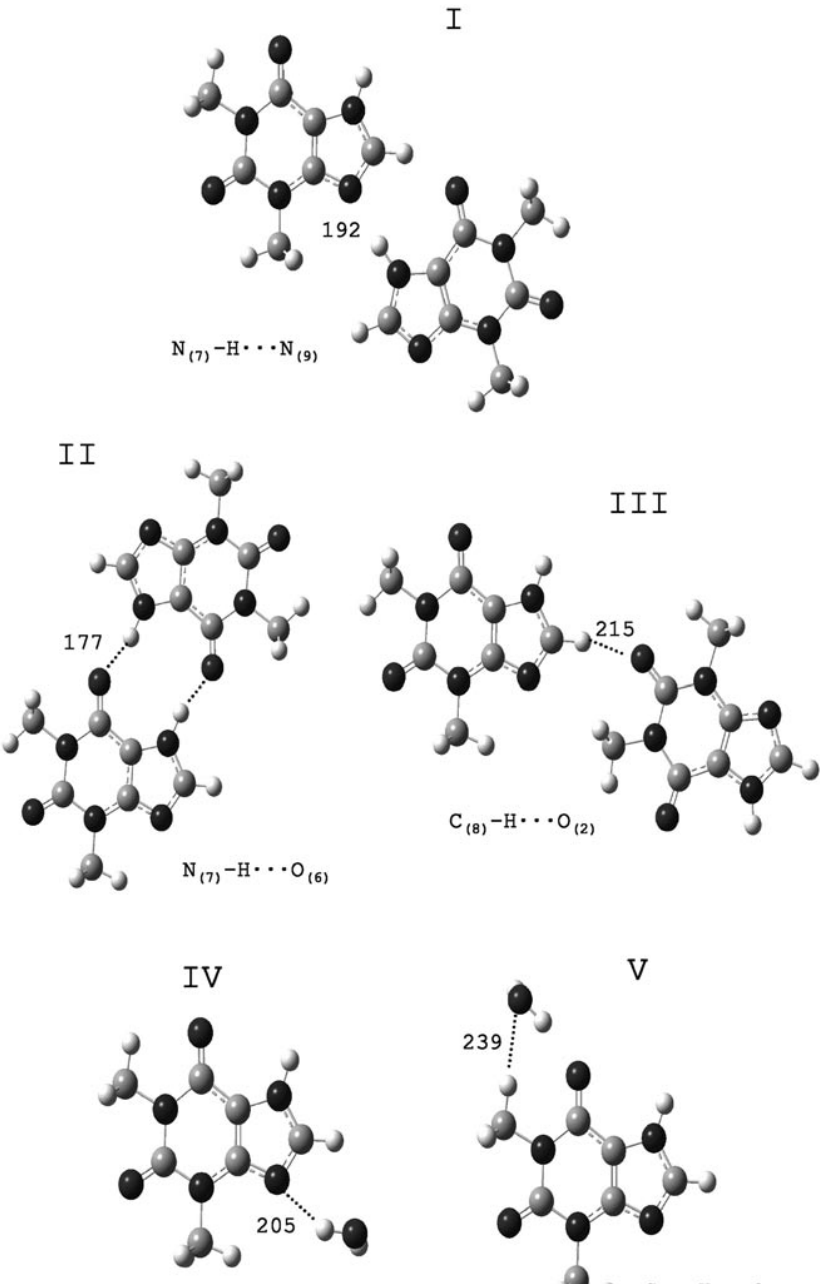

$\mathrm{N}_{(9)} \cdots \mathrm{H}-\mathrm{O}_{\mathrm{w}}$

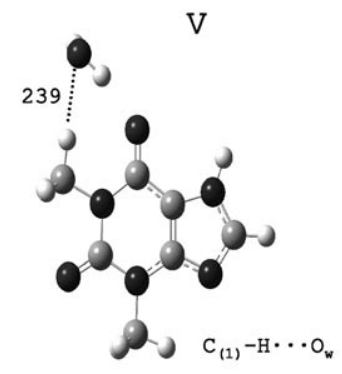

Figure 3. Optimized structures of the molecular pairs selected to describe the intermolecular contacts in the crystal structure of theophylline anhydrous (TPa, pair I) and theophylline monohydrate (TPh, pairs II-V), showing the calculated $\mathrm{H} \cdots \mathrm{N}$ and $\mathrm{H} \cdots \mathrm{O}$ distances in pm.
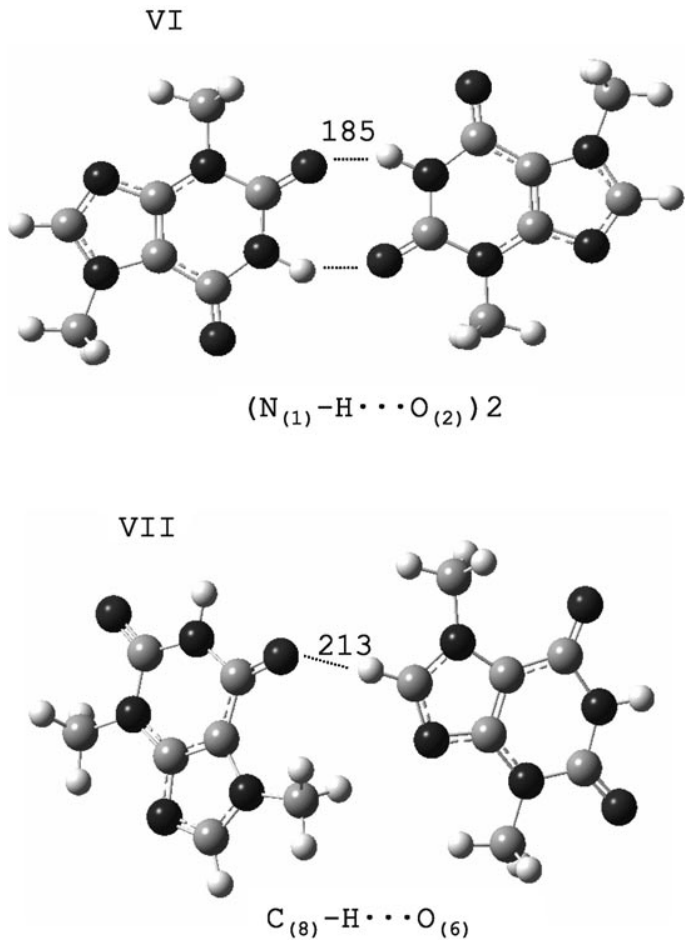

Figure 4. Optimized structures of the molecular pairs selected to describe the intermolecular contacts in the crystal structure of anhydrous theobromine (TBa). Calculated $\mathrm{H} \cdots \mathrm{O}$ distances in $\mathrm{pm}$.

The crystal structure of the CAh was determined in 1958 by Sutor $^{[30]}$ and confirmed in 1997 by Edwards and co-workers. ${ }^{[2]}$ In this structure, the imidazole nitrogen atom of the CA molecule establishes a hydrogen bond with a water molecule of crystallization, $\mathrm{N}_{(9)} \cdots \mathrm{H}-\mathrm{O}_{\mathrm{w}}$ (molecular pair IX of Figure 5). The water molecules are disordered and the distance between water oxygen atoms in the channel is only $2.5 \AA .{ }^{[35]}$

The strong $\mathrm{N}_{(9)} \cdots \cdot \mathrm{H}-\mathrm{O}_{\mathrm{w}}$ hydrogen bond results in the activation of the neighboring $\mathrm{C}_{(8)}-\mathrm{H}$ as hydrogen bond donor. ${ }^{[14]}$ In the crystal structure of $\mathrm{CAh}$, the $\mathrm{C}_{(8)} \cdots \mathrm{O}_{(2)}$ intermolecular distance is $3.1 \AA$ (and consequently, $\mathrm{H} \cdots \mathrm{O}_{(2)}$ distance $\left.\approx 2.1 \AA \AA\right)^{[10,12]}$ This evidences the existence of molecular pairs kept by $\mathrm{C}_{(8)}$ $\mathrm{H} \cdots \mathrm{O}_{(2)}$ hydrogen bonds (molecular pair VIII of Figure 5). Additionally, there is also proof of molecular pairing through $\mathrm{C}_{(7)}-$ $\mathrm{H} \cdots \mathrm{O}_{(6)}$ (represented by the molecular pair $X$ of Figure 5). The calculated stabilizing effect of these molecular associations follows the order IX $>$ VIII $>X$, in agreement with the results of Carlucci and Gavezzoti, using a higher level of calculations. ${ }^{[35]}$ It also follows the expected pat- 

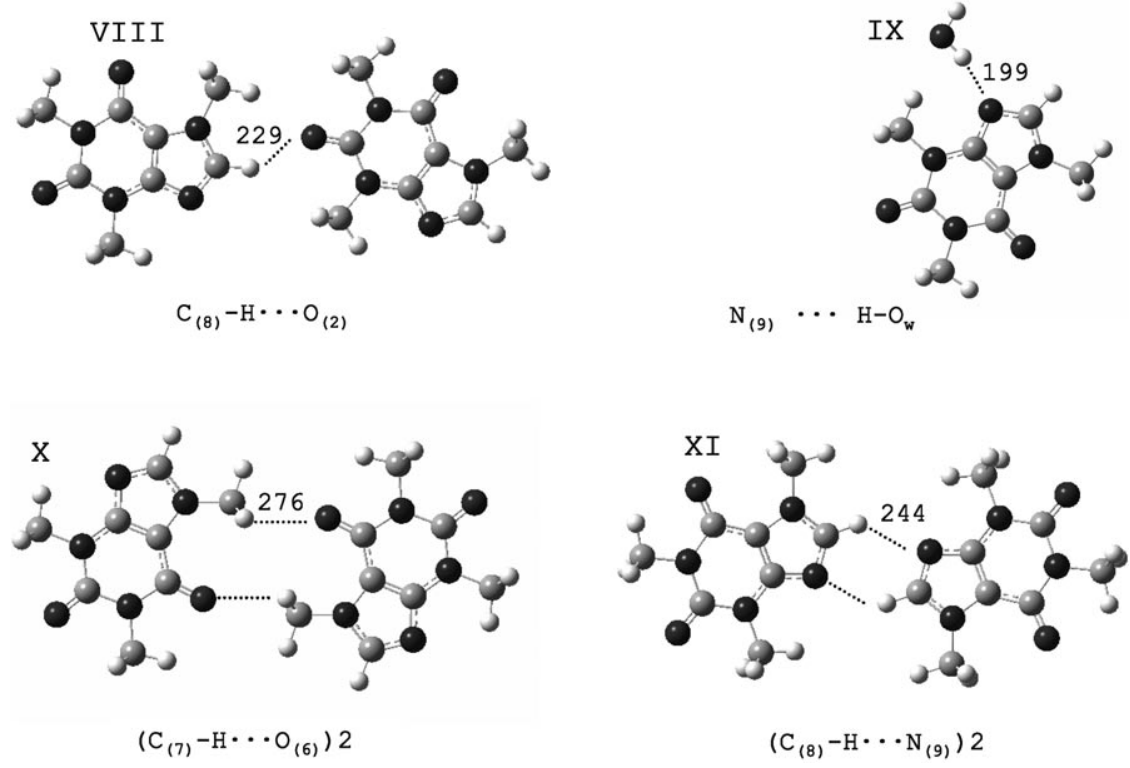

Figure 5. Optimized structures of the molecular pairs selected to describe the intermolecular contacts in the crystal structure of caffeine monohydrate (CAh, pairs VIII-X). Also included is the molecular pair XI describing a possible intermolecular contact in the anhydrous caffeine form (CAa). Calculated $\mathrm{H} \cdots \mathrm{N}$ and $\mathrm{H} \cdots \mathrm{O}$ distances in pm.

\subsubsection{Theophylline}

The application of Equation (2) to TP is straightforward for the modes listed in Table 1, as the predicted wavenumbers for each normal mode are obtained by simply adding the predicted shifts to the calculated value for the monomer. For instance, considering the $\beta \mathrm{C}=\mathrm{O}$ modefirst line of Table 1 -its predicted wavenumbers are $363+10=$ $373 \mathrm{~cm}^{-1}$ for TPa and $363+$ $27=390 \mathrm{~cm}^{-1}$ for TPh. Thus, this mode is assigned to the observed bands at 377 and $388 \mathrm{~cm}^{-1}$ in the Raman spectra of $\mathrm{TPa}$ and $\mathrm{TPh}$, respectively. The same procedure is applied to the modes presenting smaller shifts and not shown in Table 1.

Figure 6 compares the experitern of the intermolecular interaction strength, $\mathrm{N}_{(9)} \cdots \cdot \mathrm{H}-\mathrm{O}_{\mathrm{w}}>$ $\mathrm{C}_{(8)}-\mathrm{H} \cdots \mathrm{O}_{(2)}>\mathrm{C}_{(7)}-\mathrm{H} \cdots \mathrm{O}_{(6)}$.

In the CAa form, the $\mathrm{N}_{(9)}$-atom is no longer blocked by the water molecule and can be used by another $\mathrm{H}$-bond donor group. In order to assess new insights into the possible structure of CAa crystal, several other molecular associations, presenting the $\mathrm{N}_{(9)}$-atom as the $\mathrm{H}$-bond acceptor, are tested. A relevant one is the association of two CA molecules by weak $\mathrm{C}_{(8)}-\mathrm{H} \cdots \mathrm{N}_{(9)}$ hydrogen bonds (molecular pair XI of Figure 5), due to its stabilization energy. This molecular pair has already been considered among the most probable in crystalline CAa by Carlucci and Gavezzoti, although these authors do not assign any structure-driving importance to weak $\mathrm{C}-\mathrm{H} \cdots \mathrm{O} / \mathrm{N}$ bonds. ${ }^{[35]}$

Tables 2 and 3 present the predicted ab initio wavenumbers for the monomer and the wavenumber shifts promoted by considering the different molecular pairs for TB and CA forms, respectively (only the modes that are significantly affected by the intermolecular contacts are shown).

\subsection{Vibrational Assignments Using the Computationally Assisted Methodology}

In this section, the complete assignment of the FT-Raman and FTIR spectra of the three methyl-xanthine derivatives is presented in the light of the above discussed structural features, namely, the effect of the intermolecular interactions present in each system through Equation (2). It should be mentioned that due to the strong coupling of oscillators in some normal modes, the approximate description of the modes presented below is based on the highest contribution for each vibrational mode. In a few cases, the unavoidable hybrid nature of the vibrational mode is indicated in the approximate description with a plus sign (e.g. $v \mathrm{CC}+v \mathrm{CN}$ modes). mental and calculated (for the isolated TP molecule and for the different molecular pairs considered) FT-Raman spectra of TPa and TPh in the $1000-1800 \mathrm{~cm}^{-1}$ region (the complete IR and Raman spectra of both TP forms are published elsewhere ${ }^{[22]}$ ). The application of the computationally-assisted methodology in the assignment of the vibrational spectra is also illustrated, since the $1000-1800 \mathrm{~cm}^{-1}$ wavenumber region is particularly sensitive to the structural differences between TPa and TPh. As can be seen from Figure 6, there are a number of spectral changes on going from the predicted

\begin{tabular}{|c|c|c|c|c|}
\hline \multirow[t]{2}{*}{ Monomer } & \multicolumn{3}{|c|}{$\begin{array}{l}\text { Predicted wavenumber shifts } / \mathrm{cm}^{\cdot 1} \\
\text { TBa }\end{array}$} & \multirow[t]{2}{*}{$\begin{array}{l}\text { Approximate } \\
\text { description }^{[\mathrm{a}]}\end{array}$} \\
\hline & VI & VII & Sum(VI+VII) & \\
\hline 151 & 10 & & 10 & butterfly \\
\hline 213 & & 12 & 12 & $\beta \mathrm{N}(7)-\mathrm{C}\left(\mathrm{H}_{3}\right)$ \\
\hline 229 & & 10 & 10 & $\delta$ pyr ring \\
\hline 400 & 15 & & 15 & $\beta C=0$ \\
\hline 685 & -18 & & -18 & $\gamma C=0$ \\
\hline 624 & 251 & & 251 & $\gamma \mathrm{N}(1) \mathrm{H}$ \\
\hline 802 & & 76 & 76 & $\gamma \mathrm{C}(8) \mathrm{H}$ \\
\hline 1214 & & 13 & 13 & $\beta C(8) \mathrm{H}$ \\
\hline 1305 & 15 & & 15 & $v \mathrm{CC}+v \mathrm{CN}$ \\
\hline 1356 & 71 & & 71 & $\beta \mathrm{N}(1) \mathrm{H}$ \\
\hline 1475 & 10 & 13 & 23 & $\delta_{\mathrm{as}} \mathrm{C}(3) \mathrm{H}_{3}$ \\
\hline 1486 & -11 & -10 & -21 & $\delta_{\text {as }} \mathrm{C}(7) \mathrm{H}_{3}$ \\
\hline 1725 & -33 & -24 & -57 & $v \mathrm{C}=\mathrm{O}$ \\
\hline 1738 & -10 & -11 & -21 & $v \mathrm{C}=\mathrm{O}$ \\
\hline 3468 & -284 & & -284 & $v \mathrm{~N}(1) \mathrm{H}$ \\
\hline
\end{tabular}




\begin{tabular}{|c|c|c|c|c|c|c|}
\hline \multirow[b]{2}{*}{ Monomer } & \multicolumn{5}{|c|}{ Predicted wavenumber shifts $/ \mathrm{cm}^{-1}$} & \multirow[t]{2}{*}{ Approximate description ${ }^{[a]}$} \\
\hline & $\begin{array}{l}\text { CAh } \\
\text { VIII }\end{array}$ & IX & $x$ & Sum $(\mathrm{VIII-X})$ & $\begin{array}{l}\text { CAa } \\
\mathrm{XI}\end{array}$ & \\
\hline 297 & & 14 & & 14 & & $\beta \mathrm{N}(3)-\mathrm{C}\left(\mathrm{H}_{3}\right)$ \\
\hline 801 & 58 & & 10 & 68 & 58 & $\gamma \mathrm{C}(8) \mathrm{H}$ \\
\hline 1055 & & 11 & & 11 & & $\rho \mathrm{C}(7) \mathrm{H} 3+v \mathrm{~N}(1) \mathrm{C}\left(\mathrm{H}_{3}\right)$ \\
\hline 1221 & & & & & 12 & $\beta C(8) \mathrm{H}$ \\
\hline 1687 & -15 & & -10 & -25 & & $v \mathrm{C}=0$ \\
\hline 3143 & & & & & -19 & $v \mathrm{C}(8) \mathrm{H}$ \\
\hline
\end{tabular}

[a] $v=$ stretching; $\beta=$ in-plane deformation; $\gamma=$ out-of-plane deformation; $\rho=\mathrm{CH}_{3}$ rocking. single molecule (frame A) to molecular pairs I and II (frame B and $D$, respectively). Considering the information presented in Table 1, the most sensitive modes present in the 1000$1800 \mathrm{~cm}^{-1}$ spectral region are the $v \mathrm{C}=\mathrm{O}, v \mathrm{C}_{(4)}=\mathrm{C}_{(5)}, v \mathrm{CC}+\nu \mathrm{CN}$, $\beta \mathrm{C}_{(8)} \mathrm{H}$, and $\beta \mathrm{N}_{(7)} \mathrm{H}$ vibrational modes. The carbonyl stretching bands $(\nu \mathrm{C}=0)$ predicted for the monomer (1694 and $1729 \mathrm{~cm}^{-1}$ ) are not significantly affected in molecular pair I (frame B) but are clearly shifted downwards (to 1661 and $1722 \mathrm{~cm}^{-1}$ ) in molecular pair II (frame D). This shift of the carbonyl stretching modes towards lower frequencies in molecular pair II is explained by the presence of a strong $\mathrm{N}_{(7)}-\mathrm{H} \cdot \mathrm{O}_{(6)}$ hydrogen bond engaging the $\mathrm{C}_{(6)}=\mathrm{O}$ group. Molecular pair III (not included in Figure 6) also exhibits carbonyl stretching modes shifted to lower frequencies $\left(1680\right.$ and $1726 \mathrm{~cm}^{-1}$ ) due to the presence of weak $\mathrm{C}_{(8)} \mathrm{H} \cdots \mathrm{O}_{(2)}$ hydrogen bonding. Based on this data, the two carbonyl modes of TPh can be related to the pair of bands at $1658-1687 \mathrm{~cm}^{-1}$ (frame E). The corresponding modes for TPa are ascribed to the $1665-1707 \mathrm{~cm}^{-1}$ pair (frame C), somewhat far from the monomer values. This is one of the rare cases in which the limitations of the method become more evident: the $v C=0$ modes in TPa seem to be affected by long-range interactions not included in Equation (2).

The in-plane bending modes of the $\mathrm{N}_{(7)} \mathrm{H}$ and $\mathrm{C}_{(8)} \mathrm{H}$ groups $\left(\beta \mathrm{N}_{(7)} \mathrm{H}\right.$ and $\beta \mathrm{C}_{(8)} \mathrm{H}$, respectively) are predicted to occur in the monomer (frame A) at 1381 and $1217 \mathrm{~cm}^{-1}$, respectively. However, the formation of the intermolecular interactions $\mathrm{N}_{(7)} \mathrm{H} \cdots \mathrm{N}_{(9)}$ (molecular pair I) and $\mathrm{N}_{(7)} \mathrm{H}_{\cdots} \mathrm{O}_{(6)}$ (molecular pair II) shifts the $\beta \mathrm{N}_{(7)} \mathrm{H}$ and $\beta \mathrm{C}_{(8)} \mathrm{H}$ to lower and higher frequencies, respectively. The $\beta \mathrm{N}_{(7)} \mathrm{H}$ is downward shifted as a direct consequence of the formation of the $\mathrm{N}_{(7)} \mathrm{H} \cdots \mathrm{N}_{(9)}$ or $\mathrm{N}_{(7)} \mathrm{H} \cdots \mathrm{O}_{(6)}$ interactions, while the upward shift predicted for the $\beta \mathrm{C}_{(8)} \mathrm{H}$ is an indirect consequence of those interactions [an example of the indirect effect of intermolecular interactions, as described in Equation (2)]. Additionally, in the molecular pair III, the $\beta \mathrm{C}_{(8)} \mathrm{H}$ mode is also shifted to higher frequency, almost to the same extent, due to the formation of weaker $\mathrm{C}_{(8)} \mathrm{H} \cdots \mathrm{O}_{(2)}$ hydrogen bonding. Based on these results, the experimentally observed band at $1249 \mathrm{~cm}^{-1}$ in the Raman spectra of both TPa and TPh (frame $C$ and $\mathrm{E}$, respectively) can be assigned to the $\beta \mathrm{N}_{(7)} \mathrm{H}$ mode. On the other hand, the $\beta \mathrm{C}_{(8)} \mathrm{H}$ mode appears at $1426 \mathrm{~cm}^{-1}$ for the TPa form (frame C), being shifted to $1423 \mathrm{~cm}^{-1}$ on hydrate formation (frame E).

A comparison of the experimental Raman spectra of both forms (frames $C$ and $E$ ) shows that the bands at $1612\left(\nu \mathrm{C}_{(4)}=\right.$ $\left.\mathrm{C}_{(5)}\right)$ and $1570 \mathrm{~cm}^{-1}(\nu \mathrm{CC}+\nu \mathrm{CN})$ are shifted to 1607 and $1561 \mathrm{~cm}^{-1}$, respectively, upon hydrate formation. Another important criterion for the assignments herein proposed is the isotopic vibrational shifts upon $\mathrm{N}-\mathrm{H}$ deuteration. Ab initio calculations show that besides the three $\mathrm{N}-\mathrm{H}$ modes $(\nu \mathrm{NH}, \beta \mathrm{NH}$,
Figure 6. Example of methodology with theophylline anhydrous (TPa) and theophylline monohydrate (TPh). Calculated and experimental Raman spectra in the $1000-1800 \mathrm{~cm}^{-1}$ region of theophylline monomer $(A)$, molecular pair I (B), TPa (C), molecular pair II (D), and TPh (E). 
$\gamma \mathrm{NH}$ ) other modes include the motion of the $\mathrm{H}$ atom at $\mathrm{N}_{(7)}$ and thus are significantly affected by the H/D exchange.

The FT-IR spectra of TPa, TPh, and TPh ${ }_{-d}$ (hydrated deuterated TP) in the $500-1000$ and $2000-3600 \mathrm{~cm}^{-1}$ regions are shown in Figure 7. A comparison of the FT-IR spectra in Figure 7 shows the presence of a broad band at $846 \mathrm{~cm}^{-1}$ (TPa, frame A) that is shifted to $818 \mathrm{~cm}^{-1}$ upon hydration (TPh, frame B) and disappears upon crystallization in $\mathrm{D}_{2} \mathrm{O}$, being shifted to $593 \mathrm{~cm}^{-1}\left(\mathrm{TPh}_{-\mathrm{d}}\right.$, frame $\left.\mathrm{C}\right)$. These bands are clearly ascribed to the out-of-plane bending mode of $\mathrm{N}_{(7)}-\mathrm{H}\left(\gamma \mathrm{N}_{(7)}-\mathrm{H}\right)$. The observed wavenumber shift from TPa to TPh suggests that the the $\mathrm{N}_{(7)} \mathrm{H} \cdots \mathrm{N}$ hydrogen bond in the TPa is stronger than the $\mathrm{N}_{(7)} \mathrm{H} \cdots \mathrm{O}(6)$ hydrogen bond in TPh.

The analysis of the infrared spectrum in the $2000-3600 \mathrm{~cm}^{-1}$ region is somewhat restricted by the strong broad bands due to the $\mathrm{H}_{2} \mathrm{O}$ and $\mathrm{D}_{2} \mathrm{O}$ stretching modes and the Fermi resonance effects. The FT-IR of TPh evidences a well-defined band at $3139 \mathrm{~cm}^{-1}$, which is absent in the spectrum of TPh $-\mathrm{d}$. The spectrum of $\mathrm{TPh}_{-\mathrm{d}}$, on the other hand, shows a new band at $2495 \mathrm{~cm}^{-1}$, within the range of the predicted isotopic shift. Consequently, it is reasonable to assign these two bands to the $\mathrm{N}_{(7)}-\mathrm{H}$ and $\mathrm{N}_{(7)}-\mathrm{D}$ stretching vibrations, respectively. This vibrational mode $\left(v \mathrm{~N}_{(7)}-\mathrm{H}\right)$ appears at $3061 \mathrm{~cm}^{-1}$ in the FTIR spectrum of TPa.

Figure 7 also illustrates the effects of the intermolecular interactions in the modes directly engaged in intermolecular contacts. This is particularly evident for those related to the $\mathrm{C}_{(8)}-\mathrm{H}$ group, which is engaged in $\mathrm{C}-\mathrm{H} \cdots \mathrm{O}$ hydrogen bonding in TPh. According to the vibrational frequency calculations, it is reasonable to ascribe the $\mathrm{C}_{(8)}-\mathrm{H}$ stretching mode $\left(\nu \mathrm{C}_{(8)}-\mathrm{H}\right)$ to the bands observed at 3106 and $3122 \mathrm{~cm}^{-1}$ in the spectra of TPh and TPa, respectively. This indicates a red-shift upon hydrogen bonding, characteristic of strong $\mathrm{C}-\mathrm{H}$ donors. ${ }^{[36]}$

From the vibrational modes analysis (see Table 1 ) it is predicted that the $\mathrm{C}_{(8)}-\mathrm{H}$ out-of-plane bending mode $\left(\gamma \mathrm{C}_{(8)}-\mathrm{H}\right)$ in TPh crystal should appear at $\approx 160 \mathrm{~cm}^{-1}$ above the $800 \mathrm{~cm}^{-1}$ predicted for the monomer. The strong band observed at $980 \mathrm{~cm}^{-1}$ in the FT-IR spectrum of TPh, in a region where all the remaining bands can be reasonably assigned to other vibrational modes, is thus designated to the $\gamma \mathrm{C}_{(8)}-\mathrm{H}$ mode. In $\mathrm{TPa}$, the same vibrational mode is predicted to occur at somewhat lower frequency (ca. $800+87 \mathrm{~cm}^{-1}$, Table 1), but is found at nearly the same frequency as for TPh. This can be viewed as the error limit of the method, although there is a qualitative agreement in the sense that the $\gamma \mathrm{C}_{(8)}-\mathrm{H}$ mode is significantly upward shifted from the monomer values in both TPa and TPh forms.

The complete assignment of the Raman and FT-IR spectra of $\mathrm{TPa}$ and TPh-resulting from all the data gathered and the considerations above-is presented in Table 4. Apart from the expected fundamental modes, small contaminations with the metastable polymorph of TP $\left(\mathrm{TP}_{\mathrm{m}}\right)$ can be found in the vibrational spectra. ${ }^{[11]}$

\subsubsection{Theobromine and Caffeine}

The experimental wavenumbers and proposed assignments of TBa and of CAa and CAh are summarized in Tables 5 and 6, respectively.

As stated above (and shown

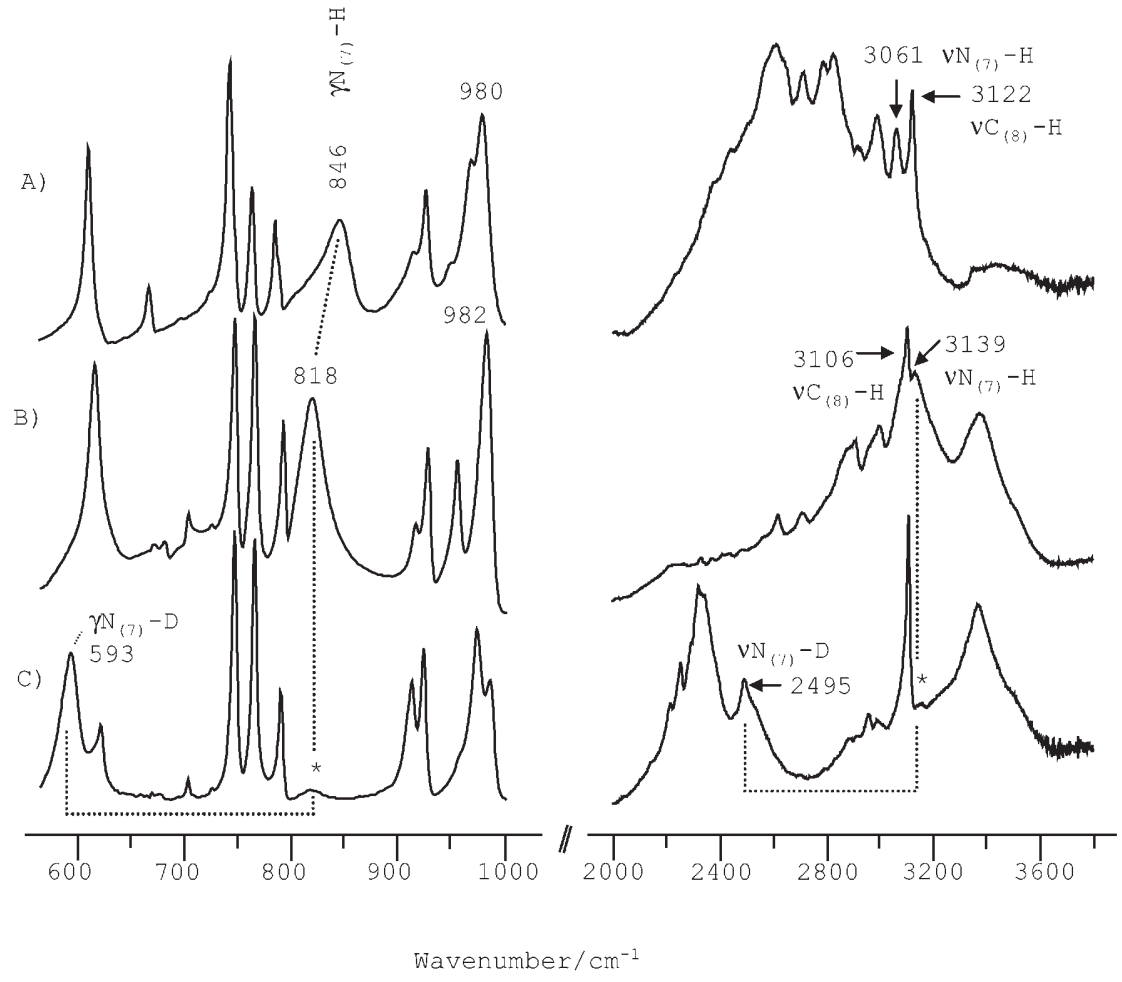

Figure 7. Infrared spectra of TPa (A), TPh (B), and $\mathrm{TPh}_{-d}(\mathrm{C})$ in the $500-1000$ and $2000-3600 \mathrm{~cm}^{-1}$ regions, with the assignments based on the isotopic shift. The weak features marked with $\left(^{*}\right)$ in spectrum $C$ are due to the residual presence of non-deuterated TPh. in Table 2), in the case of TBa the main intermolecular interactions are of the type $\mathrm{N}_{(1)} \mathrm{H} \cdots \mathrm{O}_{(2)}$ and $\mathrm{C}_{(8)} \mathrm{H} \cdots \mathrm{O}_{(6)}$. Therefore, it is expected that the most affected vibrational modes are the ones related to the $C_{(2)}=0$ and $C_{(6)}=0$ carbonyl groups, and to the $\mathrm{N}_{(1)} \mathrm{H}$ and $\mathrm{C}_{(8)} \mathrm{H}$ groups. In fact, according to ab initio calculations the $\nu \mathrm{C}=\mathrm{O}$ modes are shifted to lower frequencies upon formation of those intermolecular interactions, the effect being naturally larger in the case of the stronger $\mathrm{N}_{(1)}{\mathrm{H} \cdots \mathrm{O}_{(2)}}$ interaction $\left(\Delta v=33 \mathrm{~cm}^{-1}\right.$ and $\Delta v=$ $24 \mathrm{~cm}^{-1}$ on passing from monomer to molecular pair $\mathrm{VI}$ and to molecular pair VII, respectively). On the other hand, the out-ofplane $\mathrm{C}=\mathrm{O}(\gamma \mathrm{C}=\mathrm{O})$ mode is predicted to shift from $685 \mathrm{~cm}^{-1}$ for the monomer to $667 \mathrm{~cm}^{-1}$ for molecular pair $\mathrm{VI}$ and to $688 \mathrm{~cm}^{-1}$ for molecular pair VII. 
Table 4. Complete computationally-assisted assignments of the FT-Raman and FT-IR spectra of theophylline anhydrous (TPa) and hydrate (TPh).

\begin{tabular}{|c|c|c|c|c|c|c|}
\hline $\begin{array}{l}\text { TPa } \\
\text { Calc }^{[b]}\end{array}$ & Raman & FTIR & $\begin{array}{l}\text { TPh } \\
\text { Calc }^{[b]}\end{array}$ & Raman & FTIR & Approximate description ${ }^{[a]}$ \\
\hline 112 & 117 & - & 173 & - & - & $\tau \mathrm{C}_{(1)} \mathrm{H}_{3}$ \\
\hline 129 & 132 & - & 116 & - & - & $\gamma \mathrm{N}_{(1)}-\mathrm{CH}_{3}$ \\
\hline 150 & 164 & - & 167 & 179 & - & Butterfly motion \\
\hline 193 & 211 & - & 191 & 192 & - & $\zeta \mathrm{pyr}$ \\
\hline 293 & 305 & - & 293 & 294 & - & $\zeta \mathrm{pyr}+\beta \mathrm{N}_{(3)}-\mathrm{CH}_{3}$ \\
\hline 319 & 326 & - & 350 & 328 & - & $\beta \mathrm{N}_{(1)}-\mathrm{CH}_{3}$ \\
\hline 346 & 363 & 363 & 368 & 369 & 369 & $\zeta$ pyr \\
\hline 373 & 377 & 377 & 390 & 388 & 390 & $\beta C=0$ \\
\hline 419 & - & 420 & 437 & - & 420 & $\beta C=0$ \\
\hline 446 & 447 & 445 & 460 & 453 & 455 & $\alpha \mathrm{pyr}$ \\
\hline 501 & 504 & 503 & 503 & 502 & 499 & $\alpha$ pyr \\
\hline 538 & 555 & - & 554 & 572 & - & Pyr breathing \\
\hline - & 578 & - & - & - & - & $\mathrm{TP}_{\mathrm{m}}$ \\
\hline 591 & 612 & 611 & 605 & 614 & 615 & $\zeta$ imid \\
\hline 656 & 668 & 668 & 674 & 673 & 675 & $\alpha$ pyr \\
\hline- & 676 & - & - & - & - & $\mathrm{TP}_{\mathrm{m}}$ \\
\hline 672 & 698 & 697 & 674 & 702 & 702 & $\gamma C=0$ \\
\hline 709 & 743 & 742 & 709 & 747 & 746 & $\zeta$ imid \\
\hline 717 & 765 & 763 & 711 & 765 & 765 & $\gamma C=0$ \\
\hline
\end{tabular}

$$
-
$$$$
\text { - }
$$$$
970
$$$$
980
$$

1049

$$
-
$$

[a] $\nu=$ stretching; $\beta=$ in-plane deformation; $\gamma=$ out-of-plane deformation; $\alpha=$ in-plane ring deformation; $\zeta=$ out-of-plane ring deformation; $\delta=\mathrm{CH}_{3}$ deformation; $\rho=\mathrm{CH}_{3}$ rocking; $\tau=\mathrm{CH}_{3}$ torsion. $\mathrm{TP}_{\mathrm{m}}=$ small contamination with metastable TP form; pyr = pyrimidine, imid=imidazole; [b] Calculated values using Equation (2) (monomer + predicted shifts)

Figure 8 shows the calculated infrared spectra (in the 550$950 \mathrm{~cm}^{-1}$ region) of TB monomer (frame A), molecular pair VI (frame B), and molecular pair VII (frame C). The $\gamma \mathrm{N}_{(1)} \mathrm{H}$ and $\gamma \mathrm{C}_{(8)} \mathrm{H}$ vibrational modes are expected to occur in this spectral region. The $\gamma \mathrm{N}_{(1)} \mathrm{H}$ mode is predicted at $624 \mathrm{~cm}^{-1}$ for the monomer, being significantly shifted upwards (to $875 \mathrm{~cm}^{-1}$ ) upon establishment of the $\mathrm{N}_{(1)} \mathrm{H} \cdots \mathrm{O}_{(2)}$ hydrogen bond (molecular pair VI). On the other hand, the $\gamma \mathrm{C}_{(8)} \mathrm{H}$ mode is predicted to shift upwards by $\approx 79 \mathrm{~cm}^{-1}$ when the weaker $\mathrm{C}_{(8)} \mathrm{H} \cdots \mathrm{O}_{(6)}$ interaction is considered (molecular pair VII). As both types of interactions are present in the crystal structure of $\mathrm{TBa}$, it is expected that both the $\gamma \mathrm{N}_{(1)}-\mathrm{H}$ and $\gamma \mathrm{C}_{(8)}-$ $\mathrm{H}$ modes are observed in the $800-900 \mathrm{~cm}^{-1}$ region.

The stretching vibrations of $\mathrm{C}_{(8)}-\mathrm{H}$ and $\mathrm{N}_{(1)}-\mathrm{H}\left(\nu \mathrm{C}_{(8)}-\mathrm{H}\right.$ and $v \mathrm{~N}_{(1)}-\mathrm{H}$, respectively) are also affected by the presence of the $\mathrm{N}_{(1)}-\mathrm{H} \cdots \mathrm{O}_{(2)}$ and $\mathrm{C}_{(8)}-\mathrm{H} \cdots \mathrm{O}_{(6)}$ hydrogen bondings. According to the calculations both modes are shifted to lower frequencies on passing from the monomer to one of the two molecular pairs (VI or VII). Based on this information and on the deuteration studies, the $v \mathrm{~N}_{(1)}-\mathrm{H}$ mode was ascribed to a broad band at $3156 \mathrm{~cm}^{-1}$ in the FT-IR spectrum, while a band centered at $3116 \mathrm{~cm}^{-1}$ in the Raman spectrum was assigned to the $\nu \mathrm{C}_{(8)}-$ $\mathrm{H}$ mode.

As for TP, deuteration studies are used to confirm the assignment of the bands due to the $\mathrm{N}-\mathrm{H}$ modes in TBa. Figure 9 compares part of the FT-Raman and FT-IR spectra of TBa and $\mathrm{TBa}_{-\mathrm{d}}$ (partially deuterated TBa). As can be seen, there is a clear intensity decrease of the broad band observed at $862 \mathrm{~cm}^{-1}$ in the FT-IR spectrum upon partial deuteration. Thus, it is reasonable to ascribe this band to the 
Table 5. Complete computationally-assisted assignment of the FT-Raman and FT-IR spectra of theobromine anhydrous.

\begin{tabular}{|c|c|c|c|}
\hline $\mathrm{Calc}^{[\mathrm{a}]}$ & Raman & FTIR & Approximate description $^{[b]}$ \\
\hline 123 & 117 & - & $\gamma \mathrm{N}_{(7)}-\mathrm{CH}_{3}$ \\
\hline 161 & 169 & - & Butterfly motion \\
\hline 209 & 188 & - & $\zeta \mathrm{pyr}$ \\
\hline 225 & 225 & - & $\beta \mathrm{N}_{(7)}-\mathrm{CH}_{3}$ \\
\hline 239 & 256 & - & $\zeta$ pyr \\
\hline 313 & 321 & - & $\beta \mathrm{N}_{(3)}-\mathrm{CH}_{3}$ \\
\hline 370 & 375 & 373 & $\zeta \mathrm{pyr}+\beta \mathrm{C}=0$ \\
\hline 415 & 415 & 420 & $\beta C=0$ \\
\hline 460 & 460 & 456 & $\alpha$ pyr \\
\hline 496 & 509 & 507 & $\alpha$ pyr \\
\hline 591 & 621 & 615 & pyr breathing $+\zeta$ imid \\
\hline 665 & 675 & 680 & $\alpha$ pyr \\
\hline 667 & 696 & 691 & $\gamma C=0$ \\
\hline 705 & 734 & 732 & $v \mathrm{CC}+\nu \mathrm{CN}$ \\
\hline 713 & 751 & 751 & $\gamma C=0$ \\
\hline 723 & 766 & 763 & $\zeta$ imid \\
\hline 764 & 778 & 783 & $\alpha$ imid \\
\hline 876 & - & 862 & $\gamma \mathrm{N}_{(1)}-\mathrm{H}$ \\
\hline 876 & 888 & 888 & $\gamma \mathrm{C}_{(8)}-\mathrm{H}$ \\
\hline 926 & 946 & 940 & $\alpha$ imid \\
\hline 1025 & 1040 & 1040 & $v \mathrm{~N}_{(3)}-\mathrm{CH}_{3}$ \\
\hline 1056 & 1072 & 1071 & $\rho \mathrm{C}_{(7)} \mathrm{H}_{3}(\mathrm{ip})$ \\
\hline 1122 & 1138 & 1140 & $v \mathrm{CC}+v \mathrm{CN}+\rho \mathrm{C}_{(7,3)} \mathrm{H}_{3}(\mathrm{oop})$ \\
\hline 1160 & 1177 & 1172 & $v \mathrm{CC}+v \mathrm{CN}$ \\
\hline 1200 & 1208 & 1204 & $\rho \mathrm{C}_{(3)} \mathrm{H}_{3}(\mathrm{ip})$ \\
\hline 1227 & 1226 & 1225 & $\beta \mathrm{C}_{(8)}-\mathrm{H}$ \\
\hline 1275 & 1298 & 1294 & $v \mathrm{CC}+\nu \mathrm{CN}$ \\
\hline 1320 & 1334 & 1334 & $v \mathrm{CC}+\nu \mathrm{CN}$ \\
\hline 1346 & 1363 & 1365 & $v \mathrm{~N}_{(7)}-\mathrm{CH}_{3}$ \\
\hline 1379 & 1394 & 1392 & Imid breathing \\
\hline 1426 & 1411 & 1410 & $\beta \mathrm{N}_{(1)}-\mathrm{H}$ \\
\hline 1422 & 1426 & 1424 & $\delta_{\mathrm{as}} \mathrm{C}_{(7,3)} \mathrm{H}_{3}$ \\
\hline 1450 & 1455 & 1455 & $\delta_{\text {as }} \mathrm{C}_{(7)} \mathrm{H}_{3}+v \mathrm{CC}+v \mathrm{CN}+\delta_{\text {as }} \mathrm{C}_{(3)} \mathrm{H}_{3}$ \\
\hline 1498 & 1480 & 1480 & $\delta_{\text {as }} \mathrm{C}_{(3)} \mathrm{H}_{3}$ \\
\hline 1465 & 1489 & 1486 & $\delta_{\text {as }} \mathrm{C}_{(7)} \mathrm{H}_{3}$ \\
\hline 1534 & 1552 & 1548 & $v \mathrm{CC}+\nu \mathrm{CN}$ \\
\hline 1572 & 1594 & 1592 & $v \mathrm{C}_{(4)}=\mathrm{C}_{(5)}$ \\
\hline 1668 & 1685 & 1690 & $\nu \mathrm{C}=\mathrm{O}$ \\
\hline 1717 & 1708 & 1710 & $v \mathrm{C}=\mathrm{O}$ \\
\hline 2966 & 2956 & 2951 & $v_{\mathrm{as}} \mathrm{C}_{(7,3)} \mathrm{H}_{3}$ \\
\hline 3023 & 3002 & 3001 & $v_{\mathrm{as}} \mathrm{C}_{(3)} \mathrm{H}_{3}$ \\
\hline 3040 & 3025 & 3025 & $v_{\mathrm{as}} \mathrm{C}_{(7)} \mathrm{H}_{3}$ \\
\hline 3073 & 3037 & 3040 & $v_{\text {as }} \mathrm{C}_{(3)} \mathrm{H}_{3}$ \\
\hline 3144 & 3116 & 3117 & $v \mathrm{C}_{(8)}-\mathrm{H}$ \\
\hline 3184 & 3157 & 3156 & $v \mathrm{~N}_{(1)}-\mathrm{H}$ \\
\hline
\end{tabular}

[a] Calculated values using Equation (2) (monomer + predicted shifts) [b] $v=$ stretching; $\beta=$ in-plane deformation; $\gamma=$ out-of-plane deformation; $\alpha=$ in-plane ring deformation; $\xi=$ out-of-plane ring deformation; $\delta=\mathrm{CH}_{3}$ deformation; $\rho=\mathrm{CH}_{3}$ rocking; $\tau=\mathrm{CH}_{3}$ torsion; $\mathrm{pyr}=$ pyrimidine, $\mathrm{imid}=$ imidazole.

$\gamma \mathrm{N}_{(1)}-\mathrm{H}$. In addition, based on the ab initio results, the closelying band at $888 \mathrm{~cm}^{-1}$ is assigned to the $\gamma \mathrm{C}_{(8)}-\mathrm{H}$ mode.

It should be mentioned that there is an excellent agreement between the predicted shifts in Table 2 and those actually observed in the vibrational spectra of TBa (see Table 5). The only exception is the $\gamma \mathrm{C}=\mathrm{O}$ mode, whose predicted wavenumber is $685 \pm 18 \mathrm{~cm}^{-1}$ and is observed at $691 \mathrm{~cm}^{-1}$.

Caffeine (CA) presents a particular vibrational problem. In contrast to what is observed for TP and TB, the vibrational spectra of the anhydrous and monohydrated forms (CAa and
Table 6. Complete computationally-assisted assignment of the FT-Raman and FTIR spectra of caffeine anhydrous (CAa) and hydrate (CAh).

\begin{tabular}{|c|c|c|c|c|c|c|}
\hline \multicolumn{3}{|c|}{ CAa } & \multicolumn{3}{|l|}{ CAh } & \multirow[t]{2}{*}{ Approximate description ${ }^{[a]}$} \\
\hline Calc $c^{[b]}$ & Raman & FTIR & $\operatorname{Calc}^{[\mathrm{b}]}$ & Raman & FTIR & \\
\hline 124 & 106 & - & 120 & 109 & - & $\gamma \mathrm{N}_{(7)}-\mathrm{CH}_{3}$ \\
\hline 128 & 143 & - & 130 & 128 & - & $\gamma \mathrm{N}_{(1)}-\mathrm{CH}_{3}$ \\
\hline 164 & 164 & - & 174 & 168 & - & Butterfly motion \\
\hline 212 & 227 & - & 222 & 217 & - & $\beta \mathrm{N}_{(7)}-\mathrm{CH}_{3}$ \\
\hline 219 & 235 & - & 227 & 238 & - & $\zeta_{p} p y r$ \\
\hline 277 & 282 & - & 281 & 292 & - & $\xi \mathrm{pyr}$ \\
\hline 297 & 315 & - & 311 & 319 & - & $\beta \mathrm{N}_{(3)}-\mathrm{CH}_{3}$ \\
\hline 359 & 373 & 371 & 359 & 375 & 373 & $\beta \mathrm{N}_{(1)}-\mathrm{CH}_{3}+\zeta \mathrm{pyr}$ \\
\hline 398 & 391 & 390 & 398 & 389 & 388 & $\beta C=0$ \\
\hline 413 & 425 & 425 & 409 & - & 425 & $\beta C=0$ \\
\hline 446 & 445 & 444 & 453 & 447 & 444 & $\alpha$ pyr \\
\hline 487 & 484 & 481 & 491 & 487 & 481 & $\alpha$ pyr \\
\hline 536 & 556 & - & 538 & 556 & - & pyr breathing \\
\hline 602 & 610 & 609 & 604 & 612 & 612 & $\zeta$ imid \\
\hline 625 & 644 & 644 & 630 & 647 & 647 & $\alpha$ pyr \\
\hline 672 & 698 & 700 & 671 & 699 & 700 & $\gamma C=0$ \\
\hline 718 & 742 & 745 & 718 & 744 & 745 & $\zeta$ imid $+\gamma \mathrm{C}=\mathrm{O}$ \\
\hline 729 & - & 759 & 728 & 762 & 762 & $v \mathrm{CC}+v \mathrm{CN}$ \\
\hline 785 & 802 & 800 & 785 & 805 & 803 & $v \mathrm{CC}+v \mathrm{CN}$ \\
\hline 859 & 863 & 860 & 869 & 888 & 888 & $\gamma \mathrm{C}(8)-\mathrm{H}$ \\
\hline 912 & 929 & 927 & 915 & 929 & 926 & $\alpha$ imid \\
\hline 961 & 976 & 974 & 959 & 978 & 975 & $\alpha$ imid \\
\hline 1009 & 1023 & 1026 & 1010 & 1027 & 1026 & $\rho \mathrm{C}_{(1)} \mathrm{H}_{3}(\mathrm{ip})$ \\
\hline 1055 & 1072 & 1070 & 1066 & 1076 & 1075 & $\rho \mathrm{C}_{(7)} \mathrm{H}_{3}(\mathrm{ip})+v \mathrm{~N}_{(1)}-\mathrm{CH}_{3}$ \\
\hline 1114 & 1134 & 1130 & 1109 & 1130 & 1130 & $\rho \mathrm{C}_{(7,1,3)} \mathrm{H}_{3}(\mathrm{oop})$ \\
\hline 1181 & 1190 & 1187 & 1170 & 1192 & 1192 & $\rho \mathrm{C}_{(3)} \mathrm{H}_{3}(\mathrm{ip})$ \\
\hline 1202 & 1212 & 1212 & 1198 & 1214 & 1212 & $v \mathrm{~N}_{(3)}-\mathrm{CH}_{3}$ \\
\hline 1233 & 1241 & 1239 & 1221 & 1242 & 1239 & $\beta \mathrm{C}_{(8)}-\mathrm{H}$ \\
\hline 1238 & 1251 & - & 1236 & 1256 & 1257 & $v \mathrm{CC}+v \mathrm{CN}$ \\
\hline 1265 & 1285 & 1286 & 1260 & 1290 & 1289 & $v \mathrm{CC}+v \mathrm{CN}$ \\
\hline 1316 & 1329 & 1326 & 1320 & 1333 & 1329 & $v \mathrm{CC}+v \mathrm{CN}$ \\
\hline 1341 & 1361 & 1358 & 1353 & 1361 & 1359 & $v \mathrm{~N}_{(7)}-\mathrm{CH}_{3}$ \\
\hline 1375 & 1390 & 1390 & 1373 & 1392 & 1391 & imid breathing \\
\hline 1405 & 1404 & 1401 & 1405 & 1410 & 1412 & $\delta_{\text {as }} \mathrm{C}_{(1,7)} \mathrm{H}_{3}$ \\
\hline 1425 & 1431 & 1430 & 1432 & 1435 & 1432 & $\delta_{\text {as }} \mathrm{C}_{(3)} \mathrm{H}_{3}$ \\
\hline 1456 & 1458 & 1456 & 1456 & 1456 & 1455 & $\delta_{\mathrm{as}} \mathrm{C}_{(7,3,1)} \mathrm{H}_{3}+v \mathrm{CC}+\nu \mathrm{CN}$ \\
\hline 1472 & 1469 & - & 1472 & 1475 & 1471 & $\delta_{\mathrm{as}} \mathrm{C}_{(1,3)} \mathrm{H}_{3}$ \\
\hline 1488 & 1491 & 1485 & 1490 & - & 1489 & $\delta_{\text {as }} \mathrm{C}_{(7)} \mathrm{H}_{3}$ \\
\hline 1532 & 1554 & 1549 & 1534 & 1553 & 1550 & $v \mathrm{CC}+v \mathrm{CN}$ \\
\hline 1578 & 1600 & 1599 & 1570 & 1606 & 1602 & $v \mathrm{C}_{(4)}=\mathrm{C}_{(5)}$ \\
\hline 1687 & 1656 & 1658 & 1662 & 1655 & 1658 & $v \mathrm{C}=\mathrm{O}$ \\
\hline 1722 & 1698 & 1701 & 1715 & 1698 & 1704 & $v \mathrm{C}=\mathrm{O}$ \\
\hline 2963 & 2959 & 2955 & 2963 & 2959 & 2955 & $v_{\text {as }} \mathrm{C}_{(1)} \mathrm{H}_{3}+v_{\text {as }} \mathrm{C}_{(7)} \mathrm{H}_{3}+v_{\text {as }} \mathrm{C}_{(3)} \mathrm{H}_{3}$ \\
\hline 3026 & 3017 & - & 3028 & 3011 & 3007 & $v_{\text {as }} \mathrm{C}_{(1)} \mathrm{H}_{3}$ \\
\hline 3029 & 3035 & - & 3031 & 3027 & - & $v_{\text {as }} \mathrm{C}_{(3)} \mathrm{H}_{3}$ \\
\hline 3124 & 3114 & 3111 & 3143 & 3122 & 3122 & $v \mathrm{C}_{(8)}-\mathrm{H}$ \\
\hline- & - & - & - & - & 3375 & $v_{\mathrm{as}} \mathrm{OH}\left(\mathrm{H}_{2} \mathrm{O}\right)$ \\
\hline- & - & - & - & 3392 & - & $v_{\text {as }} \mathrm{OH}\left(\mathrm{H}_{2} \mathrm{O}\right)$ \\
\hline
\end{tabular}

[a] $v=$ stretching; $\beta=$ in-plane deformation; $\gamma=$ out-of-plane deformation; $\alpha=$ inplane ring deformation; $\zeta=$ out-of-plane ring deformation; $\delta=\mathrm{CH}_{3}$ deformation; $\rho=\mathrm{CH}_{3}$ rocking; $\tau=\mathrm{CH}_{3}$ torsion; pyr = pyrimidine, imid =imidazole. [b] Calculated values using Equation (2) (monomer + predicted shifts).

CAh) are very similar, showing only slight intensity changes and/or frequency shifts for a few spectral features. The nonsensibility of the vibrational spectra to the crystal packing is also predicted by the ab initio calculations; as shown in Table 3, only a small number of modes are found to be affected by the intermolecular interactions considered.

Figure 10 illustrates this similarity, by comparing the FT-IR spectra of CAa (frame A) and CAh (frame B). As it can be seen, 


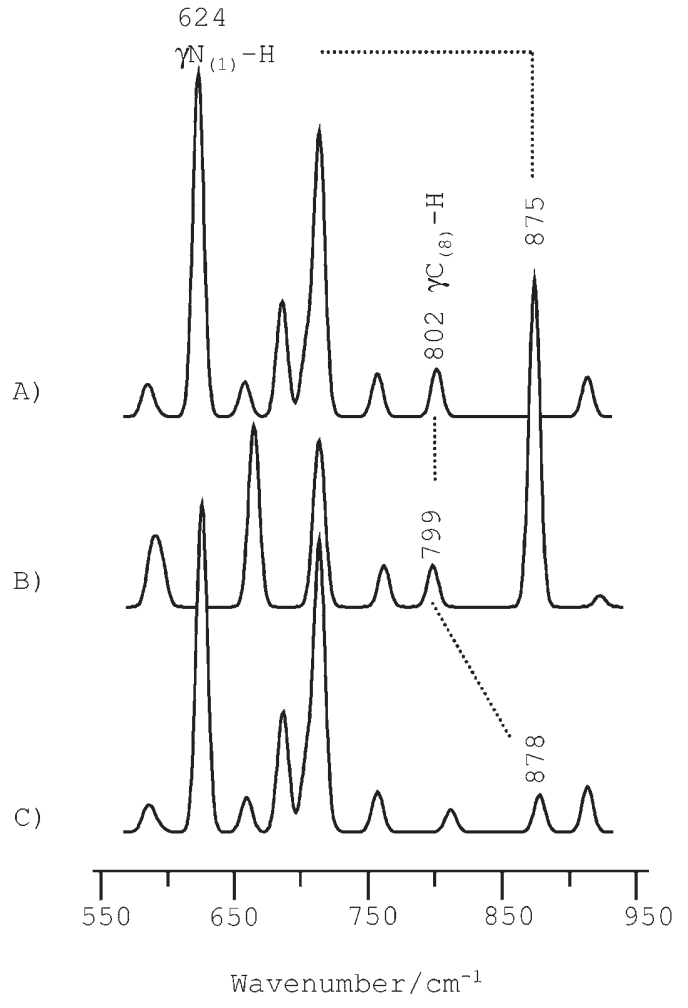

Figure 8. Calculated infrared spectra of TB in the $550-950 \mathrm{~cm}^{-1}$ region: monomer (A), molecular pair VI (B), and molecular pair VII (C)

the $\nu \mathrm{C}=\mathrm{O}$ region remains nearly unchanged on passing from CAh to CAa, apart from the intensity increase of the higher wavenumber band. This observation suggests that the intermolecular interactions involving the carbonyl groups are not significantly different for the CAh and CAa forms.

A somewhat controversial spectral change occurs for the CAh band centred at $888 \mathrm{~cm}^{-1}$. On passing from CAh (frame B) to $C A a$ (frame $A$ ), this band disappears, giving rise to a broad spectral feature with maximum intensity at $860 \mathrm{~cm}^{-1}$. The $888 \mathrm{~cm}^{-1}$ band has been ascribed to the $\mathrm{H}_{2} \mathrm{O}$ libration mode by Edwards et al. ${ }^{[12]}$ However, this assignment is not supported by our deuteration studies, as the band remains unchanged in the spectrum of $\mathrm{CAh}_{-d}$ (hydrated deuterated $C A$, spectrum not shown) when only $\mathrm{D}_{2} \mathrm{O}$ molecules are present in the crystal. Based on the predicted shifts of Table 3, this band can be assigned to the $\gamma \mathrm{C}_{(8)}-\mathrm{H}$ mode.

Another significant spectral change on passing from CAh to $\mathrm{CAa}$ is observed in the region of the $v \mathrm{C}_{(8)}-\mathrm{H}$ mode. The band assigned to the $\nu \mathrm{C}_{(8)}-\mathrm{H}$ mode is

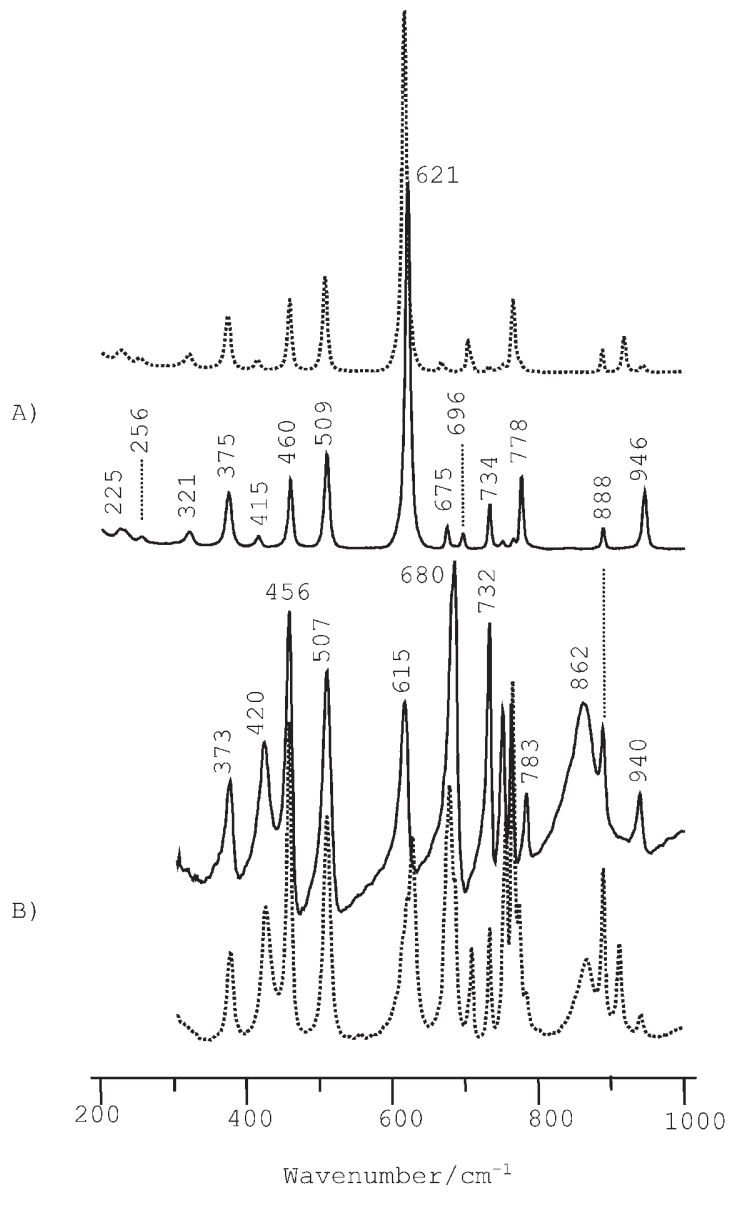

Figure 9. Raman (A) and FT-IR (B) spectra of TBa in the $200-1000 \mathrm{~cm}^{-1}$ region: normal TBa (-), deuterated TBa (-----).

shifted downwards from $\approx 3122 \mathrm{~cm}^{-1}$ in CAh to $\approx 3114 \mathrm{~cm}^{-1}$ in $\mathrm{CAa}$. This band shifting is followed by a significant intensity increase. These spectral changes upon dehydration are similar to 
those observed upon hydration in TP (downwards shifting from 3122 to $3106 \mathrm{~cm}^{-1}$ and considerable intensity increase). This comparison yields some clues concerning the intermolecular interaction patterns in the two forms (anhydrous and hydrate) of these systems.

On the whole, the spectral similarities between CAh and CAa seem to indicate that the intermolecular interaction patterns of the two forms are either similar in the donor/acceptor grouping or in the interaction strength. As no strong $\mathrm{H}$-bond donor is available in $\mathrm{CAa}$, the strongest hydrogen bond possible is of the type $\mathrm{C}_{(8)}-\mathrm{H} \ldots \mathrm{X}$, with $\mathrm{X}$ being either an $\mathrm{O}$ or an $\mathrm{N}$ atom, with the vibrational modes ascribed to the $\mathrm{C}_{(8)}-\mathrm{H}$ group being sensitive to the interactions established by the close-lying $\mathrm{N}_{(9)}$-group. Based on the ab initio calculations performed, there seems to be a higher stability upon formation of a $\mathrm{C}_{(8)}-\mathrm{H} \cdots \mathrm{N}_{(9)}$ interaction over a $\mathrm{C}_{(8)}-\mathrm{H} \cdots \mathrm{O}_{(2)}$ interaction. Thus, it is reasonable to assume that in the case of CAa the main intermolecular interaction is the van der Waals interaction, but with a contribution from a specific $\mathrm{C}_{(8)}-\mathrm{H} \cdots \mathrm{N}_{(9)}$ contact.

Attaining to the fact that the $\nu \mathrm{C}=\mathrm{O}$ region remains almost unaffected on passing from $\mathrm{CAh}$ to $\mathrm{CAa}$, it is also reasonable to consider the presence of weak $\mathrm{C}_{(1)}-\mathrm{H} \cdots \mathrm{O}_{(6)} / \mathrm{C}_{(1)}-\mathrm{H} \cdots \mathrm{O}_{(2)}$ or $\mathrm{C}_{(3)}-\mathrm{H} \cdots \mathrm{O}_{(6)} / \mathrm{C}_{(3)}-\mathrm{H} \cdots \mathrm{O}_{(2)}$ interactions in the $\mathrm{CAa}$ structure. The presence of these interactions explain to some extent the similarity observed in the carbonyl stretching bands of CAa and $\mathrm{CAh}$ and also the blue shifting of the carbon-hydrogen stretching mode involving the $\mathrm{N}$-methyl group, namely the $v_{\mathrm{as}} \mathrm{C}(1) \mathrm{H}_{3}$ and $v_{\text {as }} \mathrm{C}(3) \mathrm{H}_{3}$, on passing from CAh to CAa.

\section{Conclusions}

This study presents a new methodology (PiMM-Pairs in Molecular Materials) for the assignment of the vibrational spectra of molecular crystals, based on the ab initio evaluation of wavenumber shifts resulting from the intermolecular contacts.

The approach was tested on pharmacologically active methyl-xanthine derivatives, which are known to present pseudo-polymorphism and strong intermolecular interactions. It was found that the proposed methodology is simple, not computationally demanding, and yields reliable results. This methodology can be particularly useful in the detection and in the structural characterization of the solid-solid transformations which significantly affect the activity of a particular pharmaceutical drug.

The main errors of this methodology arise from 1) the neglecting of weak/long-range interactions and cooperativity effects, and 2) from the differences between the optimized geometry of the pairs and their arrangement in the crystal. These errors are clearly larger than those resulting from the limitations of the standard double-zeta basis set used. However, the number of inconsistencies or erroneous predictions (discussed through the text and shown in Tables 4-6) is quite low, considering the simplicity of the approach and the complexity of the systems.

A systematic investigation of both the pseudo-polymorphic transformations and intermolecular interactions occurring in theophylline, theobromine, and caffeine, as well as a complete and consistent assignment of their vibrational spectra was performed. Apart from solving some misleading assignments of the literature, this study clearly shows the relevance of vibrational spectroscopy coupled to ab initio calculations, for the study of pharmaceutical relevant drugs. As the vibrational motion is potentially different depending on the packing and conformational arrangement, the presence of different hydrogen bonds in theophylline, theobromine, and caffeine and their pseudo-polymorphs affect differently the vibrational wavenumbers, intensities, and shapes of some characteristic bands. It has been shown, as expected, that the most pseudopolymorph-sensitive modes are related to the donor and acceptor groups involved in each intermolecular hydrogen bond. In fact, considering the overall results, the vibrational modes related with the $\mathrm{C}=\mathrm{O}, \mathrm{N}-\mathrm{H}$, and $\mathrm{C}-\mathrm{H}$ groups, namely the $\nu \mathrm{C}=$ $\mathrm{O}, \nu \mathrm{N}-\mathrm{H}, \nu \mathrm{C}-\mathrm{H}, \beta \mathrm{C}-\mathrm{H}, \beta \mathrm{N}-\mathrm{H}, \gamma \mathrm{N}-\mathrm{H}$, and $\gamma \mathrm{C}-\mathrm{H}$ modes are strongly affected by intermolecular hydrogen bond formation. The study of the wavenumber shifts promoted by each contact also provides new insight into the crystal structure of caffeine anhydrous. We suggest that the presence of $\mathrm{C}_{(8)}-\mathrm{H} \cdots \mathrm{N}_{(9)}$ and $\mathrm{C}_{(1,3)}-\mathrm{H} \ldots \mathrm{O}$ intermolecular interactions explain the differences between the vibrational spectra of hydrated and dehydrated forms of caffeine.

\section{Experimental Section and Computational Methods}

Sample Preparation: Anhydrous CA, TP. and TB were obtained commercially (Aldrich) and used without further purification. TPh was prepared by dissolving anhydrous TP in distilled water at $60^{\circ} \mathrm{C}$ until a supersaturated solution was reached. The crystals obtained were filtered from the mother liquid, allowed to dry at room temperature and relative humidity conditions, and then gently milled to powder. Crystals of CAh were prepared by a similar process, but using a water-bath at $80^{\circ} \mathrm{C}$ and stored in a sealed vessel at $92 \%$ relative humidity in the presence of potassium nitrate saturated solution at room temperature. The $\mathrm{N}$-deuterated isotopomers were prepared by a similar process.

Vibrational Spectroscopy: The FT-Raman spectra in the 70$5000 \mathrm{~cm}^{-1}$ region were recorded on a RFS-100 Bruker FT-spectrometer, using a Nd:YAG laser with excitation wavelength of $1064 \mathrm{~nm}$, with laser power set to $300 \mathrm{~mW}$. Each spectrum is the averaging of two repeated measurements of 100 scans each and $2 \mathrm{~cm}^{-1}$ resolution.

Room-temperature FTIR spectra in the $300-4000 \mathrm{~cm}^{-1}$ region were recorded with a Mattson 7000 FTIR spectrometer, using a globar source, a deuterated triglycine sulphate (DTGS) detector, and potassium bromide cells. All spectra are the average of two counts, with 64 scans each, at $2 \mathrm{~cm}^{-1}$ resolution.

It was apparent that in some experiments the sample temperature rose significantly due to laser exposure, leading either to polymorphic transformations or loss of solvent molecules. ${ }^{[37,38]}$ In order to evaluate this effect, a sample of TPh was exposed continuously to $300 \mathrm{~mW}$ laser power for $2 \mathrm{~h}$, and 24 records of $5 \mathrm{~min}$ each were collected. The comparison of the spectra shows that the first spectral change, assignable to sample heating (denoting some loss of water molecules), although still extremely subtle, became only observable after 35 min of exposure to the laser. All the FT-Raman 
spectra reported on this work (using the conditions described above) have been collected in 25 min or less.

$\mathrm{Ab}$ initio calculations: Density functional theory (DFT) calculations were performed using the Gaussian 03W program package $(G 03 W){ }^{[39]}$ The functional used throughout the calculations consist of a mixture of HF (Hartree-Fock) and DFT exchange functionals and the gradient-corrected functional of Lee, Yang, and Parr, ${ }^{[40]}$ as proposed and parameterized by Becke (standard B3LYP option of G03W). ${ }^{[41]}$

All molecular structures were fully optimized using the standard all-electron $6-31 \mathrm{G}^{*}$ basis set, using the gradient method. ${ }^{[42]} \mathrm{Har}-$ monic vibrational wavenumbers were calculated, using analytical second derivatives, for all optimized geometries in order to confirm the convergence to a minimum at the potential energy surface and to evaluate the zero-point vibrational energy corrections (ZPVE). The wavenumbers above $500 \mathrm{~cm}^{-1}$ were scaled by a factor of $0.9614 .^{[43]}$

In order to simulate and estimate the effects of the intermolecular interactions observed in the crystal structure of both anhydrous and monohydrated forms of the three methyl-xanthine derivatives, the calculations were extended to different molecular pairs. Different molecular associates, built on the basis of the crystal structures xanthine $\cdots$ xanthine and xanthine $\cdots \mathrm{H}_{2} \mathrm{O}$ intermolecular interactions, were considered and submitted to full optimization in all cases. The vibrational assignments were based on the visualization of the atomic displacements. A possible crystal structure for the roomtemperature phase of anhydrous caffeine can be found at Acta Cryst. 2002, A48 (Supl.), C265. However, contact with the authors (F. Stowasser and C. W. Lehmann) revealed that the description of intermolecular contacts in the crystal is not yet possible.

\section{Acknowledgments}

The authors acknowledge financial support from the Portuguese Foundation for Science and Technology (FCT)_Unidade de Química-Física Molecular and Laboratório Associado CICECO. MN also acknowledges FCT for a doctoral fellowship - SFRH/BD/ 18854/2004.

Keywords: ab initio calculations - crystals - IR spectroscopy · noncovalent interactions • polymorphism • Raman spectroscopy

[1] C. E. Johnson, S. VanDeKoppel, E. Myers, Am. J. Health-Syst. Pharm 2005, 62, 2518-2520.

[2] N. Ates, D. Sahin, G. Ilbay, Epilpsy Behav. 2004, 5, 645-648.

[3] J. B. Thomas, J. H. Yen, M. M. Schantz, B. J. Porter, K. E. Sharpless, J. Agric. Food Chem. 2004, 52, 3259-3263.

[4] K. C. George, S. A. Hebbar, S. P. Kale, P. C. Kesavan, J. Radiol. Prot. 1999, 19, $171-176$.

[5] G. Fini, J. Raman Spectrosc. 2004, 35, 335-337.

[6] A. Jørgensen, J. Rantanen, M. Karjalainen, L. Khriachtchev, E. Räsänen, J. Yliruusi, Pharm. Res. 2002, 19, 1285-1291.

[7] S. Airaksinen, M. Karjalainen, E. Räsänen, J. Rantanen, J. Yliruusi, Int. J. Pharm. 2004, 276, 129-141.

[8] C. M. Adeyeye, J. Rowley, D. Madu, M. Javadi, S. S. Sabnis, Int. J. Pharm. $1995,116,65-75$.

[9] N. V. Phadnis, R. Suryanarayanan, J. Pharm. Sci. 1997, 86(11), $1256-$ 1263.

[10] E. Suihko, V. P. Lehto, J. Ketolainen, E. Laine, P. Paronen, Int. J. Pharm. 2001, 217, 225-236.
[11] A. M. Amado, M. M. Nolasco, P. J. A. Ribeiro-Claro, unpublished results.

[12] H. G. M. Edwards, E. Lawson, M. de Matas, L. Shields, P. York, J. Chem. Soc., Perkin Trans. 2 1997, 1985-1990.

[13] K. A. Ford, Y. Ebisuzaki, P. D. Boyle, Acta Crystallogr. Sect. C 1998, 54, $1980-1983$.

[14] Y. Ebisuzaki, P. D. Boyle, J. A. Smith, Acta Crystallogr. Sect. C 1997, 53, $777-779$.

[15] C. Sun, D. Zhou, D. J. W. Grant, V. G. Young Jr, Acta Crystallogr. Sect. E 2002, 58, 368-370.

[16] J. de Taeye, Th. Zeegers-Huyskens, Spectrosc. Lett. 1986, 19(4), 299-310.

[17] S. Tarulli, E. J. Baran, J. Raman Spectrosc. 1993, 24, 139-141.

[18] R. A. Nyquist, S. L. Fiedler, Vib. Spectrosc. 1995, 8, 365-386.

[19] I. Pavel, A. Szeghalmi, D. Moigno, S. Cîntã, W. Kiefer, Biopolymers 2003, $72,25-37$.

[20] S. Gunasekaran, G. Sankari, S. Ponnusamy, Spectrochim. Acta A 2005, 61, $117-127$.

[21] H. G. M. Edwards, T. Munshi, M. Anstis, Spectrochim. Acta A 2005, 61, $1453-1459$.

[22] P. J. A. Ribeiro-Claro, A. M. Amado, Spectrochim. Acta A 2005, 61, $2796-$ 2797.

[23] M. de Matas, H. G. M. Edwards, E. E. Lawson, L. Shields, P. York, J. Mol. Struct. 1998, 440, 97-104.

[24] M. Schmitt, J. Popp, J. Raman Spectrosc. 2006, 37, 20-28.

[25] M. M. Nolasco, P. J. A. Ribeiro-Claro, ChemPhysChem 2005, 6, 496-502.

[26] P. D. Vaz, P. J. A. Ribeiro-Claro, Eur. J. Inorg. Chem. 2005, 1836-1840.

[27] H. I. S. Nogueira, S. M. J. Cruz, P. C. R. Soares-Santos, P. J. A. Ribeiro-Claro, T. Trindade, J. Raman Spectrosc. 2003, 34, 350- 356.

[28] A. M. Amado, M. P. M. Marques, P. J. A. Ribeiro-Claro, ChemPhysChem 2002, 3, 599-606.

[29] D. J. Sutor, Acta Crystallogr. 1958, 11, 83-87.

[30] D. J. Sutor, Acta Crystallogr. 1958, 11, 453-458.

[31] E. Suihko, J. Ketolainen, A. Poso, M. Ahlgren, J. Gynther, P. Paronen, Int. J. Pharm. 1997, 158, 47-55.

[32] A. A Naqvi, G. C. Bhattacharyya, J. Appl.Crystallogr. 1981, 14, 464-464.

[33] E. D. L. Smith, R. B. Hammond, M. J. Jones, K. J. Roberts, J. B. O. Mitchell, S. L. Price, R. K. Harris, D. C. Apperley, J. C. Cherryman, R. Docherty, J. Phys. Chem. B 2001, 105, 5818-5826.

[34] H. Bothe, H. K. Cammenga, Thermochim. Acta 1980, 40, 29-39.

[35] L. Carlucci, A. Gavezzotti, Chem. Eur. J. 2005, 11, 271- 279.

[36] P. J. A. Ribeiro-Claro, P. D. Vaz, Chem. Phys. Lett. 2004, 390, 358-361.

[37] J. Johansson, S. Pettersson, L. S. Taylor, J. Pharm. Biomed. Anal. 2002, 30, $1223-1231$.

[38] N. A. Marigheto, E. K. Kemsley, J. Potter, P. S. Belton, R. H. Wilson, Spectrochim. Acta A 1996, 52, 1571-1579.

[39] Gaussian 03, Revision B.04, M. J. Frisch, G. W. Trucks, H. B. Schlegel, G. E. Scuseria, M. A. Robb, J. R. Cheeseman, J. A. Montgomery Jr, T. Vreven, K. N. Kudin, J. C. Burant, J. M. Millam, S. S. Iyengar, J. Tomasi, V. Barone, B. Mennucci, M. Cossi, G. Scalmani, N. Rega, G. A. Petersson, H. Nakatsuji, M. Hada, M. Ehara, K. Toyota, R. Fukuda, J. Hasegawa, M. Ishida, T. Nakajima, Y. Honda, O. Kitao, H. Nakai, M. Klene, X. Li, J. E. Knox, H. P. Hratchian, J. B. Cross, C. Adamo, J. Jaramillo, R. Gomperts, R. E. Stratmann, O. Yazyev, A. J. Austin, R. Cammi, C. Pomelli, J. W. Ochterski, P. Y. Ayala, K. Morokuma, G. A. Voth, P. Salvador, J. J. Dannenberg, V. G. Zakrzewski, S. Dapprich, A. D. Daniels, M. C. Strain, O. Farkas, D. K. Malick, A. D. Rabuck, K. Raghavachari, J. B. Foresman, J. V. Ortiz, Q. Cui, A. G. Baboul, S. Clifford, J. Cioslowski, B. B. Stefanov, G. Liu, A. Liashenko, P. Piskorz, I. Komaromi, R. L. Martin, D. J. Fox, T. Keith, M. A. Al-Laham, C. Y. Peng, A. Nanayakkara, M. Challacombe, P. M. W. Gill, B. Johnson, W. Chen, M. W. Wong, C. Gonzalez, J. A. Pople, Gaussian, Inc., Pittsburgh PA, 2003.

[40] C. Lee, W. Yang, R. G. Parr, Phys. Rev. B 1988, 37, 785-789.

[41] A. Becke, J. Chem. Phys. 1993, 98, 5648-5652.

[42] P. C. Hariharan, J. A. Pople, Theor. Chim. Acta 1973, 28, 213-222.

[43] A. P. Scott, L. Radom, J. Phys. Chem. 1996, 100, 16502-16513.

Received: May 19, 2006

Revised: June 19, 2006

Published online on September 19, 2006 